Article

\title{
Adaptive Response of a Native Mediterranean Grapevine Cultivar Upon Short-Term Exposure to Drought and Heat Stress in the Context of Climate Change
}

\author{
Nikolaos Tzortzakis ${ }^{1, *}\left(\mathbb{D}\right.$, Antonios Chrysargyris ${ }^{1}$ and Aziz Aziz ${ }^{2}$ \\ 1 Department of Agricultural Sciences, Biotechnology and Food Science, Cyprus University of Technology, \\ 3036 Limassol, Cyprus; a.chrysargyris@cut.ac.cy \\ 2 Research Unit EA 4707 RIBP, SFR Condorcet FR CNRS 3417, University of Reims Champagne-Ardenne, \\ 51687 Reims, France; aziz.aziz@univ-reims.fr \\ * Correspondence: nikolaos.tzortzakis@cut.ac.cy
}

Received: 22 December 2019; Accepted: 5 February 2020; Published: 7 February 2020

\begin{abstract}
The impact of climate change on viticulture is of major importance. Several international and indigenous grapevine cultivars have been examined for their adaptive performance to drought and heat stresses. However, the underlying physiological mechanisms are not well known. In the present study we examined the short-term effects of light and moderate drought stress (DS) as well as heat stress (HS) on physiological and biochemical attributes in two grapevine cultivars: Chardonnay (international) and Xynisteri, an indigenous adapted to the specific Cypriot microclimate. Xynisteri plants exhibited decreasing leaf stomatal conductance and photosynthetic rate as well as increasing total phenols and antioxidant capacity under DS conditions. These reactions were concomitant to a rapid accumulation of hydrogen peroxide and lipid peroxidation in leaves, associated to an increase of the antioxidant superoxide dismutase activity. However, Chardonnay plants did not exhibit the same responses as Xynisteri against DS (i.e., stomatal closure, total phenolics and antioxidants) over the first four days. Additionally, Chardonnay showed leaf damage with increased lipid peroxidation levels and activation of catalase and peroxidase. Interestingly, HS increased leaf stomatal conductance and decreased total phenolic content, flavonoids and antioxidant capacity in Chardonnay after $20 \mathrm{~d}$ of stress. In both cultivars, HS had milder effects compared to DS, and again Xynisteri showed better performance than Chardonnay in terms of damage index and antioxidative activities. Overall, Xynisteri adaptation to DS and HS was higher than that of Chardonnay, and both cultivars reacted more to the short-term DS than to HS. Although the Xynisteri performances under stress conditions provide an important resource for adaptation to stressful conditions, the impacts on earliness, yield and grape quality remain to be explored.
\end{abstract}

Keywords: climate change; drought stress; heat stress; photosynthesis; antioxidants; lipid peroxidation

\section{Introduction}

Plants will be increasingly challenged by climate change characterized by frequent and severe events of heat and drought. Long-living trees have particularly evolved a diversity of adaptive mechanisms to minimize their fitness costs under stressful conditions [1]. These adaptations operate at the physiological and molecular levels and involve regulation of stomatal opening, change of photosynthetic rate, Rubisco activity and chlorophyll binding proteins at the chloroplast, imbalance in redox homeostasis, production of reactive oxygen species (ROS) and synthesis of protective compounds and enzymes [2-6]. Plants can also cope with environmental challenges by altering leaf structure by 
lowering the leaf area/volume ratio, increasing leaf rolling, having smaller and more dense stomata, decreasing epidermal cells size, increasing elasticity of the cell wall, leaf cuticle, lignification and cell inclusions, such as mucilage, starch and crystals [7-9]. In fruit trees, physiological responses mainly depend on morphological traits (leaf size, leaf length, width) and anatomical traits (leaf thickness, palisade and spongy parenchyma). Leaf anatomical structure, especially that of the palisade and spongy parenchyma, is a very important factor for leaf photosynthetic rates because it may affect photosynthesis by changing the $\mathrm{CO}_{2}$ diffusion rate from ambient air to carboxylation sites in the chloroplast [10]. Moreover, a greater extent of palisade parenchyma is reflected with more frequent sap movement (due to higher vessel density in stem anatomy) [11] and transmission of water and minerals to the main leaves, vegetative shoots and fruits [12].

The Mediterranean basin and Europe, in general, have a significant tradition and contribution to viticulture industry. They are major key players with the largest wine production and vineyard areas in the word [13]. Grapevine (Vitis vinifera L.) cultivation in the Mediterranean region is often subjected to multiple abiotic/environmental stresses, including high air temperature, increased solar radiation, strong winds, long drying periods and water scarcity, while these stresses are maximized during the summer period $[14,15]$. In general, plants that grow in open fields are subjected to various stresses at the same time that could affect many of their physiological properties.

Grapevines cultivated in the Mediterranean area are commonly exposed to drought stress (DS) because of the clear/no cloudy sky, high evapotranspiration and low soil water availability [16], which have the potential to alter plant physiology, nutrition and metabolism [17]. Due to global warming and the increased length of the dry periods, climate change (CC) is one of the most discussed issues. Multiple studies aim to understand, explain and prevent its detrimental impacts on living organisms and the environment. To estimate the overall impacts of any single or combination of CC-related factor(s), several regional climate models have been presented $[13,18,19]$. Moreover, different irrigation strategies (deficit irrigation, treated waste water, partial root drying, irrigation systems, etc.) are explored in order to increase the water use efficiency for irrigation [20,21].

The rise of temperature because of climate change is reflected by heat stress (HS) conditions that affect a plant's physiology and development. Within the last 30 years, temperature has shown an increment of $1.8^{\circ} \mathrm{C}$ in the Mediterranean region [22]. Despite the great number of grape cultivars (about 10,000 cultivars documented in the Vitaceae [23]), the effects of CC-related factors on grape cultivars have been well documented [24]. In general, temperature is commonly known to affect vine physiology, vegetative and reproductive cycles, as well as the quality of harvested grapes, as reviewed by de Orduna [24]. This results in the acceleration of plant metabolic activities, fruit maturation and earliness of harvesting [19], affecting also wine quality and of course marketability [24,25].

When grapevines are exposed to high temperatures, lipids replace starch in leaf chloroplasts [26]. In temperatures $>30^{\circ} \mathrm{C}$, berry size and weight are decreased [27], and metabolic processes and sugar accumulation may be retarded or completely paused [28]. Aroma of white wines is favored in cool climates along with accumulation of isoprenoids and pyrazines, while sun exposure is necessary for monoterpene accumulation that may impart fruity, floral or spicy aromas [22,24]. Until now, there are no convincing data on the effects of high temperatures on aroma compounds, while accumulation of anthocyanins in berries is decreased [29,30]. Moreover, the effect of high temperature on aroma compounds is discussed in Pons et al. [31].

Both drought and heat are known to affect cell metabolism, leading to reactive oxygen species (ROS) production. This negatively affects plant metabolism through oxidative damage of lipids, proteins and nucleic acids [32,33]. Plants react to oxidative stress by increasing their capacity to scavenge or detoxify ROS through the activation of antioxidative enzymes and accumulation of nonenzymatic components [34]. The antioxidative enzymes include superoxide dismutase (SOD), catalase (CAT), peroxidase (POX), glutathione peroxidase (GPX), glutathione $S$-transferases (GST), ascorbate peroxidase (APX) and glutathione reductase (GR), while nonenzymatic antioxidant molecules are represented by ascorbate, glutathione, $\alpha$-tocopherol, proline and so forth. The high levels of both 
enzymatic and nonenzymatic antioxidants are associated with low lipid peroxidation under stress conditions [35] and are also connected to stress tolerance [34].

Climate change fingerprints show that soil and air temperature will increase in the near future, with a consequence of high water demands for irrigation, especially for susceptible cultivars. Sustainable grapevine irrigation management either by selected techniques (i.e., regulated deficit irrigation, partial root drying and/or low-quality irrigation water by using treated waste water) or by selecting cultivars with proven better performances towards environmental stresses is attracting scientific interest [14]. The objective of the current study was to elucidate and compare a commercial (Chardonnay) and a native (Xynisteri) grapevine cultivar in terms of their physiological responses to CC-related abiotic stress, such as drought and heat stress. Several grapevine growth parameters, soil properties and physiological and biochemical stress markers have been examined in response to the above stressors. Xynisteri is the most wide-spread white grape cultivar in the Cypriot vineyard, and according to farmer observations, Xynisteri performs well in high temperatures and drought conditions. Therefore, the evaluation of drought and heat tolerance properties of this cultivar compared to the international Chardonnay cultivar may enhance local viticulture resources under climate change.

\section{Materials and Methods}

\subsection{Grapevine Cultivars and Experimental Set Up}

The present study implemented at the experimental farm of the Cyprus University of Technology, Limassol, Cyprus, during spring-summer period. Two white grapevine (Vitis vinifera L.) cultivars were used, one wide-spread commercial (Chardonnay) and one native Cypriot (Xynisteri). Chardonnay is a sensitive cultivar to drought stress [36], while Xynisteri is observed by farmers as a tolerant cultivar. A total of sixty, one-year-old grapevine cuttings for each cultivar were grown in $8 \mathrm{~L}$ pots containing soil taken from the original vineyards of both Chardonnay and Xynisteri cultivation, to avoid soil variation and maintain steady plant growth. Soil had a clay-loam texture, with $2.19 \%$ organic matter; total $\mathrm{CaCO}_{3}$ $66.9 \%$; $\mathrm{pH} 7.42$; electrical conductivity (EC) $0.28 \mathrm{mS} \mathrm{cm}^{-1}$. The soil physicochemical properties during short-term $(4,8$, and $20 \mathrm{~d})$ DS or HS were determined ( $\mathrm{pH}, \mathrm{EC}$, organic matter, available $\mathrm{CaCO}_{3}$, and nitrogen $(\mathrm{N})$, potassium $(\mathrm{K})$, phosphorus $(\mathrm{P})$ and sodium $(\mathrm{Na})$ content) as described previously [21], and selected results are presented in Table S1. The region's climate is dry with a summer (June-August) rainfall of less than $30 \mathrm{~mm}$. Average day and night temperature and relative humidity during stress study for outdoor and indoor (greenhouse) set up derived by meteorological stations are shown in Figure S1.

Cuttings were collected (early January) from the commercial vineyards following common pruning agronomical practices, and then they were buried in soil until March for rooting. Rooted cuttings were planted in the pots and pruned during spring to a two-bud spur. Two shoots were allowed to grow after the bud break. During the first 3.5 months, plants were uniformly irrigated to soil capacity every day through a drip irrigation system. Irrigation needs during that period were adjusted by weighting selected pots containing cuttings with a balance, and the delivered amount of water was adjusted to reach the initial control weight (full irrigation). Before and after adjustment, the volumetric water content (VWC) was recorded on the same pots. Thereafter, each cultivar (15 plantlets in each treatment) was given different levels of irrigation, based on the measurement on the VWC. The study was divided into two subexperiments, namely, drought stress (DS) and heat stress (HS). The DS experiment had three treatments: (i) well-watered plants with full irrigation regime (FI) as a control, in which plants were irrigated every day to soil capacity; (ii) light water stress (LS), in which plants received $80 \%$ of the total water provided to well-watered plants during the week; and (iii) moderate water stress (MS), in which the plants received only $50 \%$ of the total water provided to full irrigation plants during the week. The HS experiment had two treatments: (i) well-watered plants with full irrigation regime (FI) as a control, in which plants were outdoors and were irrigated every day to soil capacity and (ii) full irrigated plants under heat stress (HS) treatment, in which the plants were grown inside a greenhouse 
(with increased temperature of $+8-9^{\circ} \mathrm{C}$ ) and irrigated every day to soil capacity. Different parameters were measured at 4,8 and $20 \mathrm{~d}$. Volumetric water content in soil was measured every 2-3 d by a field-scout TDR300 with $20 \mathrm{~cm}$ rods (Spectrum Technologies Inc, Aurora, IL, USA), as presented in Figure 1.
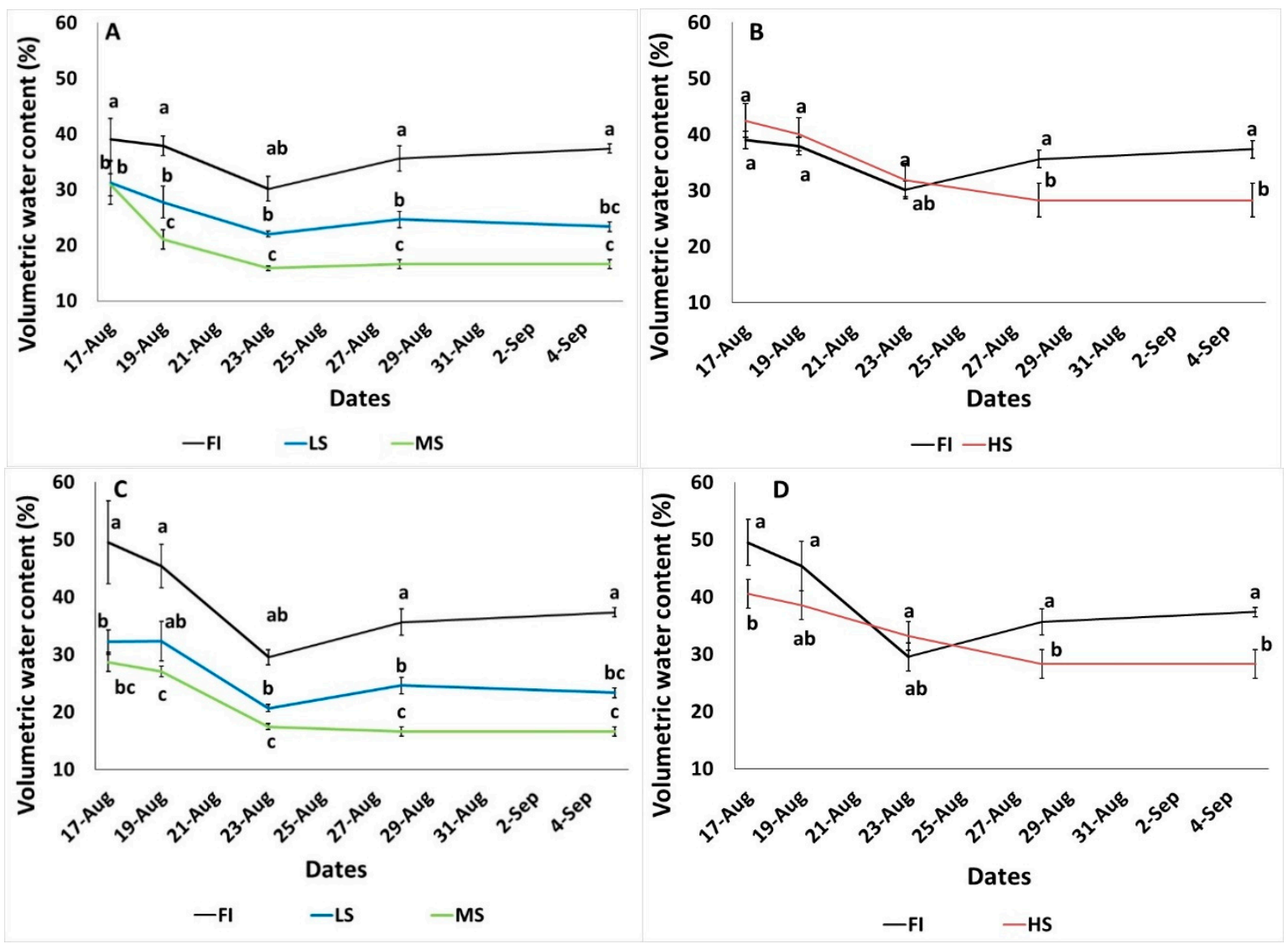

Figure 1. Impact of short-term drought and heat stress on soil volumetric water content in two grapevine cultivars, Chardonnay (A,B) and Xynisteri (C,D). Vegetative cuttings from both cultivars grown in pots were submitted to full irrigation (FI); light water stress (LS) with $80 \%$ of the FI, moderate water stress (MS) with $50 \%$ of the FI, and heat stress (HS). Data are means \pm SE $(n=4)$, and significant differences $(P<0.05)$ among treatments for the different dates are indicated by different letters $(a, b, c, a b, b c)$.

\subsection{Physiological Parameters}

Leaf tissue (four replications per treatment; each replicate consisted of a pool of plant tissue; $0.1 \mathrm{~g}$ ) was incubated in a heat bath at $65^{\circ} \mathrm{C}$ for $30 \mathrm{~min}$, in the dark, with $10 \mathrm{~mL}$ dimethyl sulfoxide (DMSO) for chlorophyll extraction. Photosynthetic pigments, i.e., chlorophyll a (Chl a), chlorophyll $\mathrm{b}(\mathrm{Chl} \mathrm{b})$ and total chlorophyll (total $\mathrm{Chl}$ ) contents were calculated as described by Chrysargyris et al. [37]. Maximum $F_{v} / F_{m}$ photochemical quantum yields of photosystem II (PSII) were measured with an OptiSci OS-30p Chlorophyll Fluorometer (Opti-Sciences). To this end, leaves were incubated in the dark for 20 min prior to $\mathrm{F}_{\mathrm{v}} / \mathrm{F}_{\mathrm{m}}$ measurements. Leaf photosynthetic rate $(p n)$, stomatal conductance $(\mathrm{gs})$ and internal leaf concentration of $\mathrm{CO}_{2}(\mathrm{Ci})$ were measured using a portable infra-red gas analyzer (Li-6400, Li-Cor, Biosciences, Lincoln, USA). Measurements of $p n, g$ s and $C i$ were carried out between 9:00-11:20AM, when the leaf temperature within the chamber was $28 \pm 2{ }^{\circ} \mathrm{C}$, with photon flux density of $1200 \mu \mathrm{mol} \mathrm{m}^{-2} \mathrm{~s}^{-1}$ at ambient $\mathrm{CO}_{2}$ concentration. The Li-6400 was equipped with a leaf chamber with constant area inserts $\left(6.0 \mathrm{~cm}^{2}\right)$. All gas-exchange measurements started $3 \mathrm{~h}$ after the onset of the photoperiod and were replicated with four plants for each treatment and two fully expanded, healthy, sun-exposed leaves per plant. 


\subsection{Polyphenol Content and Antioxidant Activity}

Total phenolics were determined with the Folin-Ciocalteu method at $755 \mathrm{~nm}$ according to Chondraki et al. [38], and results were expressed as equivalents of gallic acid per gram of fresh weight (mg of GAE $\mathrm{g}^{-1}$ fresh weight). The antioxidant capacity was measured using the ferric reducing antioxidant power (FRAP) and 2,2'-azino-bis (3-ethylbenzothiazoline-6-sulphonic acid) (ABTS) methods, and total flavonoids content was analyzed as previously described $[39,40]$. The results for antioxidant activities were expressed as trolox equivalents ( $\mathrm{mg}$ of trolox $\mathrm{g}^{-1}$ fresh weight) and for the content of total flavonoids as rutin equivalents (mg rutin $\mathrm{g}^{-1}$ fresh weight).

\subsection{Hydrogen Peroxide and Lipid Peroxidation}

Hydrogen peroxide $\left(\mathrm{H}_{2} \mathrm{O}_{2}\right)$ content in leaves was determined as described by Chrysargyris et al. [39]. Leaf tissue (four replicates/treatment; $0.2 \mathrm{~g}$ ) was homogenized in ice-cold $0.1 \%$ trichloroacetic acid (TCA) and centrifuged at $15,000 \times \mathrm{g}$ for $15 \mathrm{~min}$, and an aliquot of the supernatant was used for the reaction mixture. The $\mathrm{H}_{2} \mathrm{O}_{2}$ concentration was evaluated using standards prepared from dilutions of $\mathrm{H}_{2} \mathrm{O}_{2}$. The absorbance was measured at $390 \mathrm{~nm}$, and results were expressed as $\mu \mathrm{mol} \mathrm{H}_{2} \mathrm{O}_{2} \mathrm{~g}^{-1}$ fresh weight.

Lipid peroxidation was assessed and measured in terms of the malondialdehyde content (MDA) [39]. Absorbance of the reaction mixture was measured at $532 \mathrm{~nm}$ and corrected at $600 \mathrm{~nm}$. The amount of MDA was determined using the extinction coefficient of $155 \mathrm{mM}^{-1} \mathrm{~cm}^{-1}$. Results were expressed as nmol of $\mathrm{MDA} \mathrm{g}^{-1}$ fresh weight.

\subsection{Antioxidative Enzyme Activities}

Fresh leaf tissue (four replicates/treatment) was homogenized using an ice-cold extraction buffer containing $1 \mathrm{mM}$ ethylenediaminetetraacetic acid (EDTA), 1\% (w/v) polyvinylpyrrolidone (PVPP), $1 \mathrm{mM}$ phenylmethylsulfonyl fluoride (PMSF) and 0.05\% Triton X-100 in $50 \mathrm{mM}$ potassium-phosphate buffer (pH 7.0). Protein content was determined using bovine serum albumin (BSA) as a standard [39].

Catalase activity (CAT) (EC 1.11.1.6) and superoxide dismutase activity (SOD) (EC 1.15.1.1) were assayed following the methods described previously [39]. Catalase activity was assayed in a reaction mixture $(1.5 \mathrm{~mL})$ containing $50 \mathrm{mM} \mathrm{K}$-phosphate buffer $(\mathrm{pH} 7.0), 10 \mathrm{mM} \mathrm{H}_{2} \mathrm{O}_{2}$ and an enzyme aliquot. The decomposition of $\mathrm{H}_{2} \mathrm{O}_{2}$ was measured at $240 \mathrm{~nm}$. The results were expressed as CAT units $\mathrm{mg}^{-1}$ of protein ( 1 unit $=1 \mathrm{mM}$ of $\mathrm{H}_{2} \mathrm{O}_{2}$ reduction $\mathrm{min}^{-1}$ ). SOD was assayed using a photochemical method; a reaction mixture $(1.5 \mathrm{~mL})$ containing $50 \mathrm{mM} \mathrm{K-phosphate} \mathrm{buffer} \mathrm{(pH} \mathrm{7.5),} 13 \mathrm{mM}$ methionine, $75 \mu \mathrm{M}$ nitro blue tetrazolium (NBT), $0.1 \mathrm{mM}$ EDTA, $2 \mu \mathrm{M}$ riboflavin and an enzyme aliquot was used. The reaction began by exposing the mixture to a light source of two $15 \mathrm{~W}$ fluorescent lamps for $15 \mathrm{~min}$, it was stopped by placing the tubes in the dark. Absorbance was determined at $560 \mathrm{~nm}$, and activity was expressed as units $\mathrm{mg}^{-1}$ of protein. Peroxidase activity (POD) (EC 1.11.1.6) was determined as described previously [41] following the increase in absorbance at $430 \mathrm{~nm}$. Calculations were performed using the coefficient of extinction of $2.47 \mathrm{mM} \mathrm{cm}^{-1}$. One POD unit was defined as the amount of enzyme to decompose $1 \mu \mathrm{mol}$ of $\mathrm{H}_{2} \mathrm{O}_{2}$ per minute. Results were expressed as units of peroxidase per milligram of protein.

\subsection{Statistical Methods}

Statistical analysis was performed using IBM SPSS version 22 comparing data means $( \pm$ SE) with one way-ANOVA, and Duncan's multiple range tests were calculated for the significant data at $P<0.05$. Measurements were done in four biological replications/treatment (each replication consisted of a pool of two to three individual measures/sample). Pairwise metabolite effect correlations were calculated by Pearson's correlation test using the R program. 


\section{Results}

\subsection{Microclimate, Soil Water Content and Soil Physicochemical Properties}

Grapevines plants were exposed to DS and HS conditions up to $20 \mathrm{~d}$, and during that period, daytime temperature averaged $30.85 \pm 0.37^{\circ} \mathrm{C}$ and $39.31 \pm 0.49^{\circ} \mathrm{C}$ for outdoors and indoors (inside the greenhouse), respectively (Figure S1). During night, temperature averaged $22.16 \pm 0.48{ }^{\circ} \mathrm{C}$ and $23.88 \pm 0.58{ }^{\circ} \mathrm{C}$ for outdoors and indoors, respectively. During HS study, indoor plants were subjected up to $42.73^{\circ} \mathrm{C}$, being the average maximum temperature recorded over the period of HS, while the maximum temperature outdoors was $33.50{ }^{\circ} \mathrm{C}$. In general, the increased temperatures during the daytime reflected relative humidity decreases (from $50.78 \%$ to $24.17 \%$ ), while the opposite occurred during night time.

The volumetric water content (VWC) in soil was in line with the levels requested with the deficit irrigation practice, i.e., $80 \%$ (LS) and 50\% (MS) of the full irrigation, as presented in Figure 1A,C. Grapevine plants grown under HS had less available water after $12 \mathrm{~d}$ of stress, as the VWC decreased up to $24.3 \%$ and $20.6 \%$ for Chardonnay and Xynisteri, respectively (Figure 1B,D).

Both cultivars were grown under the same soil from the commercial grown viticulture area of Limassol prefecture. Soil properties varied under the examined abiotic stresses, mainly the $\mathrm{pH}$, EC and $\mathrm{N}$ levels (Table S1 and Figure 2). For example, in Chardonnay, soil $\mathrm{pH}$ increased under DS and HS during the stress period of $20 \mathrm{~d}$ (Figure 2A-C). Nitrogen content in soil increased during the $20 \mathrm{~d}$ of LS but decreased at 4 and $20 \mathrm{~d}$ of MS (Figure 2A,C). Heat stress resulted in a decrease of soil organic matter, N, K and Na levels (Figure 2A-C).

In Xynisteri, soil $\mathrm{pH}$ increased during the $8 \mathrm{~d}$ of exposure to LS, while $\mathrm{P}$ content increased following LS and MS, especially after day 8 (Figure 2D,E). Heat stress decreased soil pH and increased organic matter content as well as Na levels at $4 \mathrm{~d}$, while the opposite trend was found after 8 and $20 \mathrm{~d}$ of stress (Figure 2D-F). Nitrogen levels increased at 4 and $8 \mathrm{~d}$ of HS but decreased thereafter at $20 \mathrm{~d}$ (Figure 2D-F). Potassium levels in soil were following exposure to HS.

\subsection{Physiological Parameters}

Chlorophyll content was mainly affected after $8 \mathrm{~d}$ of drought stress for Chardonnay, but such changes were produced later, at $20 \mathrm{~d}$, for the Xynisteri cultivar (Figure 3). Interestingly, chlorophyll $\mathrm{a}$, chlorophyll $\mathrm{b}$ and total chlorophyll increased at $8 \mathrm{~d}$ for Chardonnay, but decreased following longer drought stress period (i.e., $20 \mathrm{~d}$ ). In the case of Xynisteri, and in comparison with Chardonnay, chlorophyll content increased after $20 \mathrm{~d}$. Heat stress seemed to have no major effect on the chlorophyll content, with the exception for the chlorophyll $b$ content, which decreased in HS-exposed Chardonnay plants compared to the control (FI-outdoor plants) after $20 \mathrm{~d}$ of stress. However, in Xynisteri, HS significantly $(P<0.05)$ decreased $\mathrm{Chl} \mathrm{a}, \mathrm{Chl} \mathrm{b}$ and total Chl content after $20 \mathrm{~d}$ of stress (Figure 3).

Leaf photosynthetic rate, stomatal conductance, internal $\mathrm{CO}_{2}$ concentration and chlorophyll fluorescence were differently affected among the Chardonnay and Xynisteri cultivars when subjected to DS and HS (Figure 4). Chardonnay exhibited lower leaf photosynthetic rates and stomatal conductance, while in the case of Xynisteri, photosynthetic performance and stomatal conductance were maintained at high levels under controlled, fully irrigated conditions.

In Chardonnay, when subjected to DS, leaf photosynthetic rates decreased (up to 68.6\%) in drought (LS and MS) conditions compared to FI treatment (control) after $8 \mathrm{~d}$ (Figure 4). Similarly, internal $\mathrm{CO}_{2}$ concentration was decreased under MS conditions. Leaf stomatal conductance did not follow a clear trend. In the case of Xynisteri, leaf photosynthetic rates, stomatal conductance and internal $\mathrm{CO}_{2}$ concentration decreased up to $79.9 \%, 91.7 \%$ and $37.9 \%$, respectively, in MS treatment compared to the control. Chlorophyll fluorescence did not change in Chardonnay among stress and time of exposure, but it decreased in Xynisteri after $8 \mathrm{~d}$ of DS.

Xynisteri plants subjected to HS showed decreased photosynthetic rate, stomatal conductance and internal $\mathrm{CO}_{2}$ concentration, mainly after $8 \mathrm{~d}$ (Figure 4). Similarly, leaf photosynthetic rate decreased in 
Chardonnay. However, Chardonnay stomatal conductance increased in full-irrigated plants when subjected to HS even at early exposure (i.e., 4 d). No differences were found in chlorophyll fluorescence in plants subjected to HS (greenhouse) or control (outdoors) conditions.

A comparison of the photosynthetic rates among the two cultivars as affected by different levels of stress conditions through time is presented in Figure S4. Leaf photosynthetic rates were higher in Xynisteri compared to Chardonnay in full irrigation and in LS treatments (after the 8th day). Interestingly, in MS, both cultivars had similar photosynthetic rates. The levels of photosynthesis decreased in Xynisteri compared to Chardonnay after $8 \mathrm{~d}$ of HS (Figure S4).

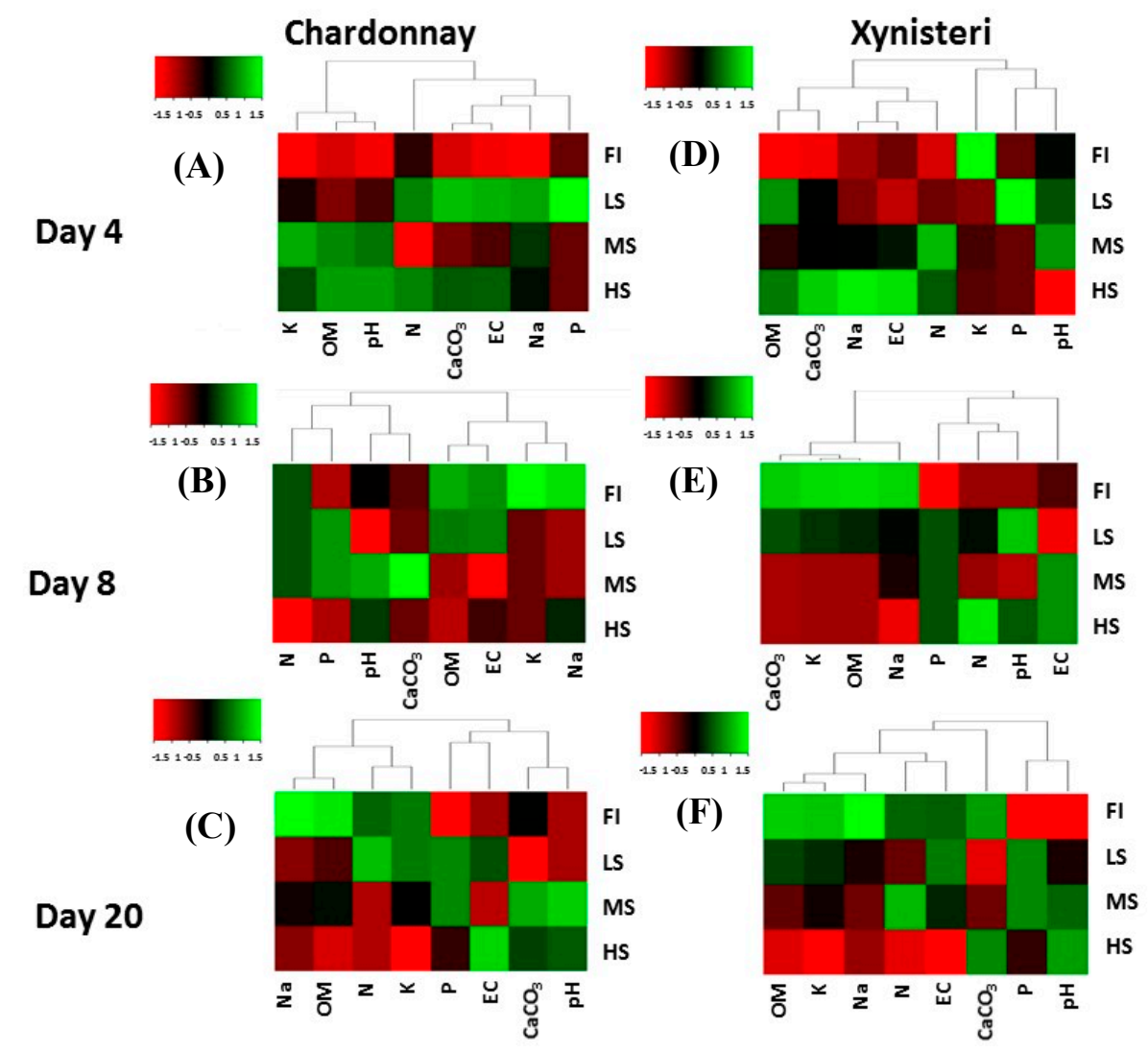

Figure 2. Relative changes in soil physicochemical properties after exposure of grapevine cultivars, Chardonnay $(\mathbf{A}-\mathbf{C})$ and Xynisteri (D-F) to water and heat stress. Heat map representing relative composition level of soil physicochemical properties after 4, 8 and $20 \mathrm{~d}$ of light water stress (LS) with $80 \%$ of the FI; moderate water stress (MS) with $50 \%$ of the FI, and heat stress (HS) as compared to control (full irrigation, FI) plants. Red shades indicate the lower level (less than -1.5 fold), deep red corresponds to -1 fold, black signifies that the level is not different from the control, deep green corresponds to 1 fold, clear green indicates that the level is more than 1.5-fold higher than the control. $\mathrm{Na}, \mathrm{N}, \mathrm{K}$ and $\mathrm{P}$ are expressed in $\mathrm{g} \mathrm{kg}^{-1}, \mathrm{CaCO}_{3}, \mathrm{OM}$ in $\%$ and $\mathrm{EC}\left(\mu \mathrm{S} \mathrm{cm}^{-1}\right)$. 

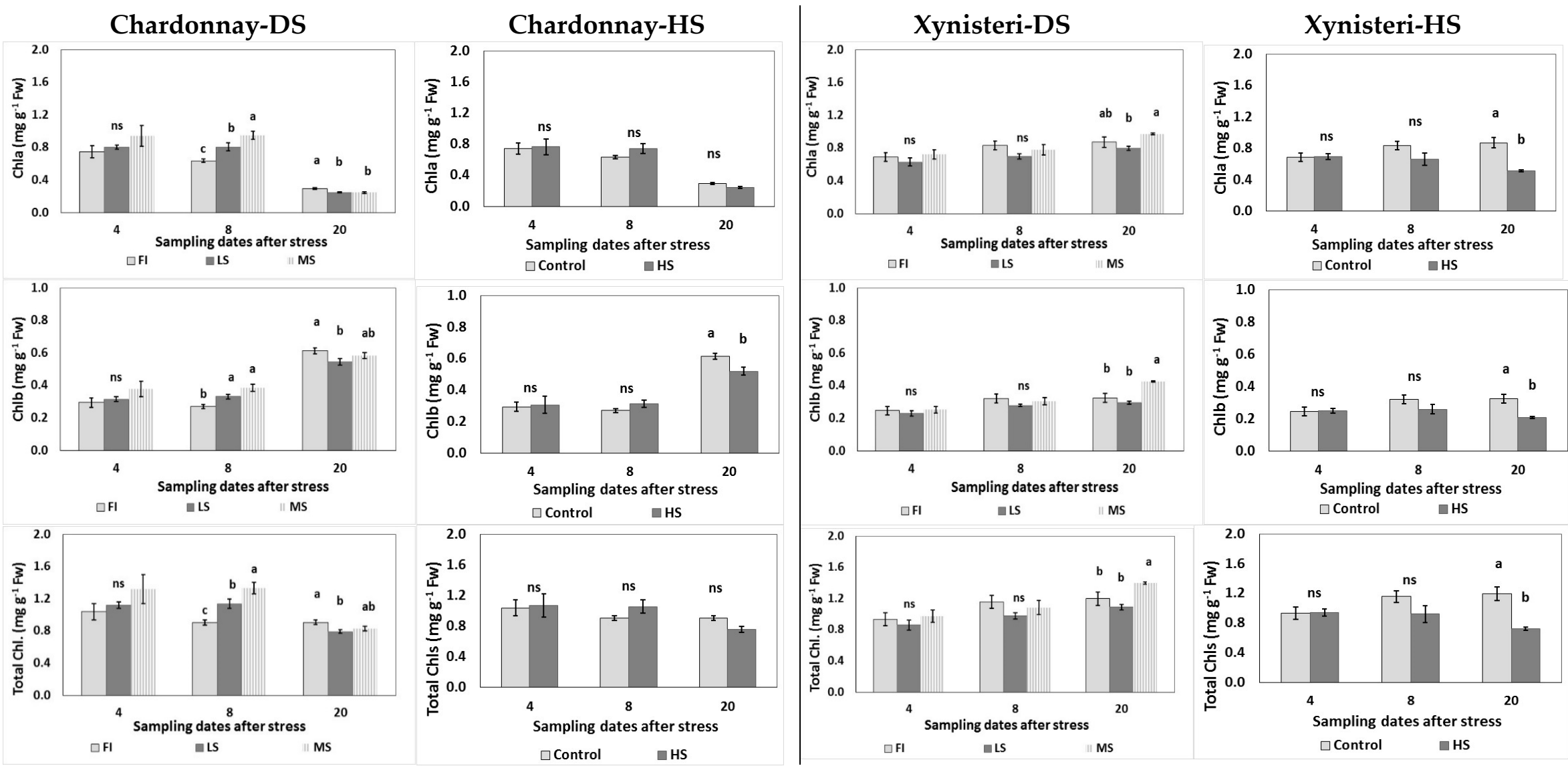

Figure 3. Impact of short-term drought and heat stress on chlorophyll content in Chardonnay and Xynisteri cultivars. Plants were full irrigated (FI) or exposed to light water stress (LS) with $80 \%$ of the FI, moderate water stress (MS) with $50 \%$ of the FI, and heat stress (HS). Chlorophyll a (Chl a), chlorophyll b (Chl b), and total chlorophyll (total Chl) were determined after 4, 8, and $20 \mathrm{~d}$ of stress. Data are means $\pm \mathrm{SE}(n=4)$, and significant differences $(P<0.05)$ among treatments are indicated by different letters (a, b, c, ab). ns: not significant. 

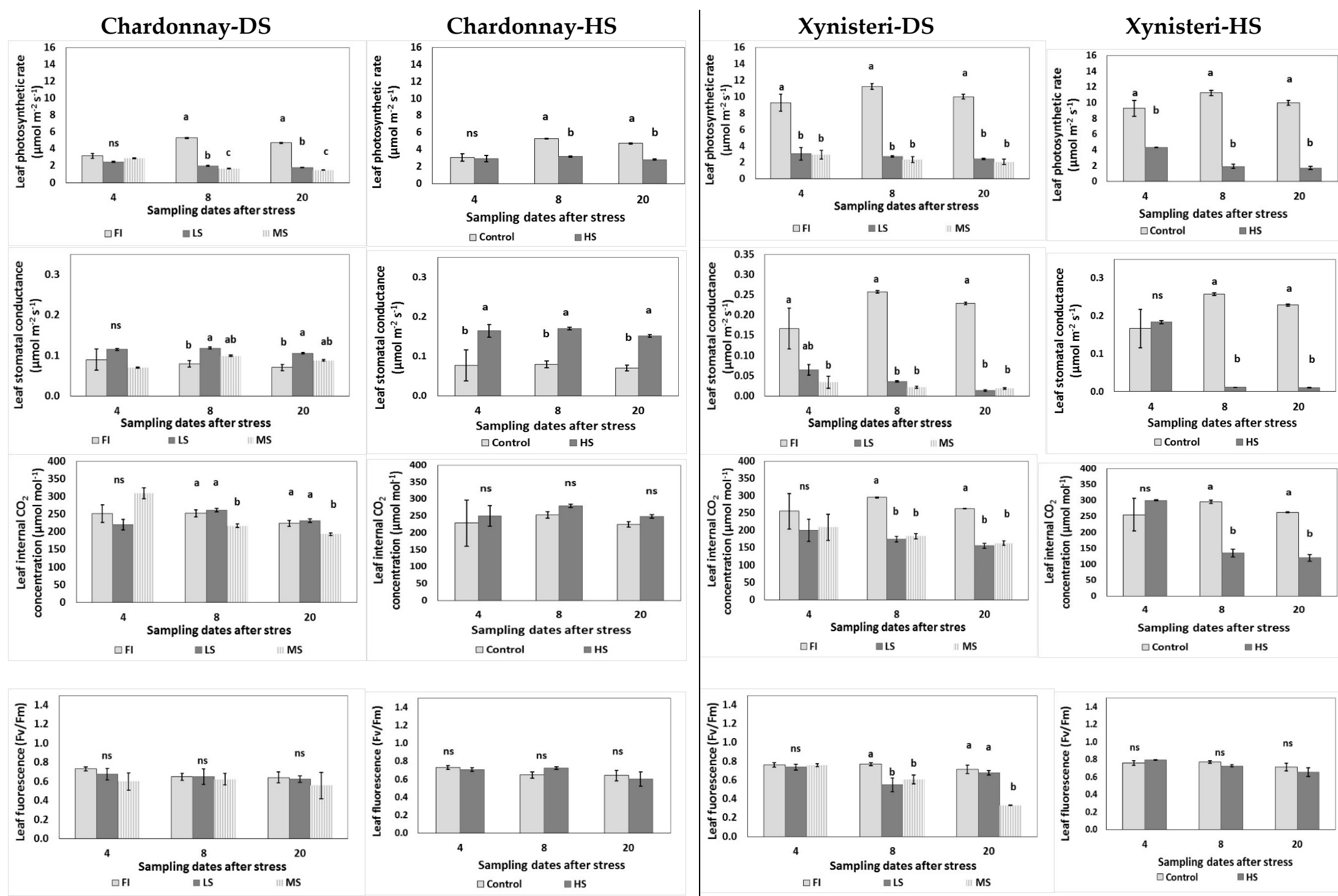
Figure 4. Impact of short-term drought and heat stress on photosynthetic rate, stomatal conductance, internal $\mathrm{CO}_{2}$ concentration and maximum PSII quantum efficiency in two grapevine cultivars, Chardonnay and Xynisteri. Plants were full irrigated (FI) or exposed to light water stress (LS) with $80 \%$ of the FI, moderate water stress (MS) with $50 \%$ of the FI, and heat stress (HS). Leaf photosynthetic rate $(P n)$, stomatal conductance $(g s)$, internal $\mathrm{CO}_{2}$ concentration $(\mathrm{Ci})$, and maximum PSII quantum efficiency $\left(\mathrm{F}_{\mathrm{v}} / \mathrm{F}_{\mathrm{m}}\right)$ were measured after 4,8 , and $20 \mathrm{~d}$ of stress. Data are means $\pm \mathrm{SE}(n=4)$, and significant differences $(P<0.05)$ among treatments are indicated by different letters. ns: not significant.

\subsection{Polyphenols, Flavonoids and Antioxidant Activity}

The effects of DS and HS on the polyphenols, flavonoids and antioxidant capacity of Chardonnay and Xynisteri are presented in Figure 5 and Figure S2. Following $20 \mathrm{~d}$ of DS, total phenolics and antioxidant activity (assayed by FRAP) in leaves were decreased in Chardonnay but were increased in Xynisteri compared to their respective controls (FI). The content of flavonoids was decreased in Chardonnay under MS conditions but was stimulated in Xynisteri after $20 \mathrm{~d}$ of LS (Figure 5 and Figure S2). Total phenolics, flavonoids and antioxidant activity (FRAP, ABTS) were decreased after $20 \mathrm{~d}$ of HS for both examined cultivars in comparison with control (outdoors). Flavonoids were also decreased in Chardonnay at $4 \mathrm{~d}$ of HS exposure.

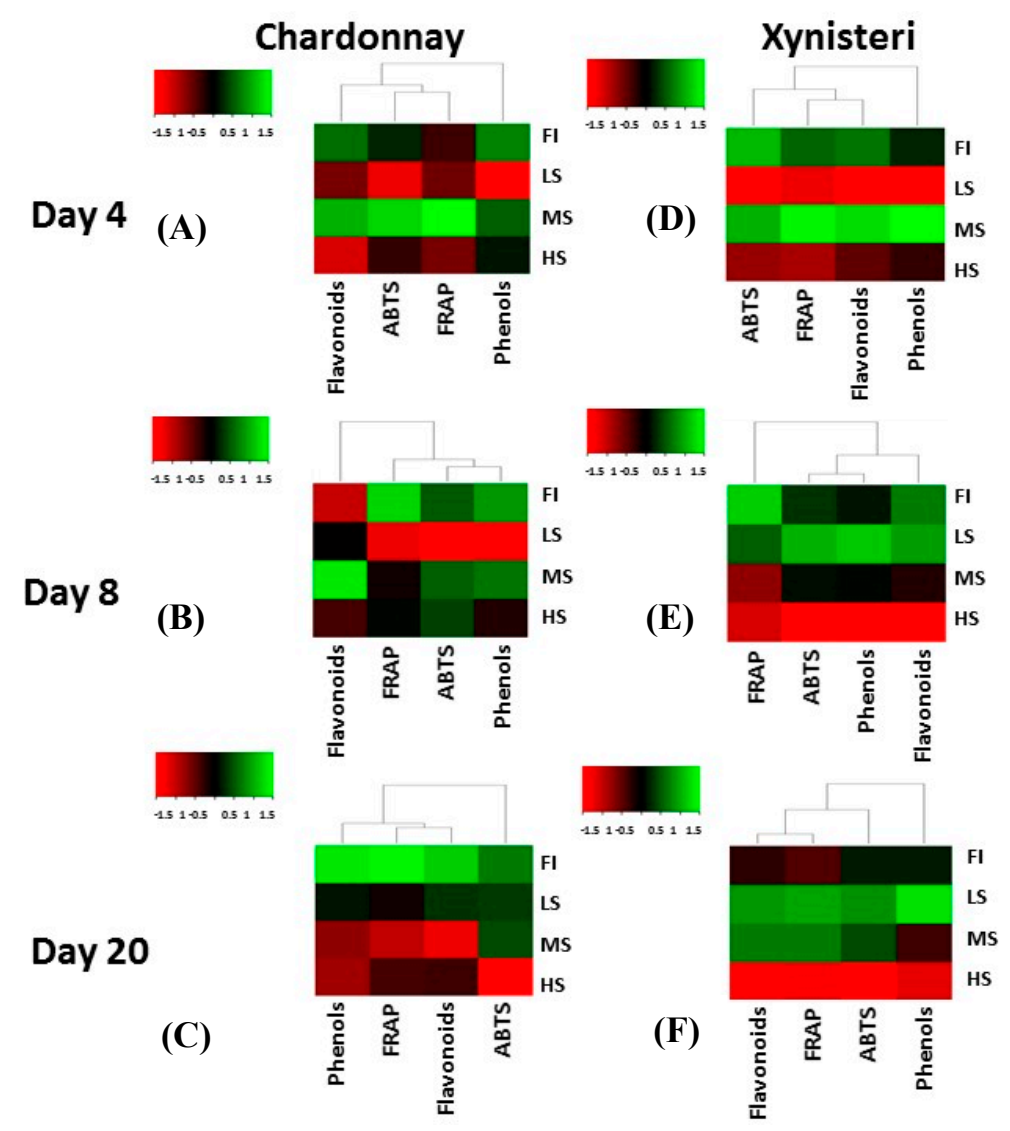

Figure 5. Relative changes in total phenols, flavonoids and antioxidant activity (FRAP, ABTS) after exposure of grapevine cultivars, Chardonnay (A-C) and Xynisteri (D-F), to water and heat stress. Heat map representing relative composition level of molecule traits after 4, 8 and $20 \mathrm{~d}$ of light water stress (LS) with $80 \%$ of the FI, moderate water stress (MS) with $50 \%$ of the FI, and heat stress (HS) as compared to control (full irrigation, FI) plants. Red shades indicate the lower level (less than -1.5 fold), deep red corresponds to -1 fold, black signifies that the level is not different from the control, deep green corresponds to 1 fold, clear green indicates that the level is more than 1.5-fold higher than the control. Total phenols are expressed as GAE $\mathrm{g}^{-1}$, flavonoids in $\mathrm{mg}$ rutin $\mathrm{g}^{-1}$ and FRAP and ABTS in mg trolox $\mathrm{g}^{-1}$. 


\subsection{Hydrogen Peroxide, Lipid Peroxidation and Antioxidative Enzyme Activity}

The impacts of short-term DS and HS on the damage index $\left(\mathrm{H}_{2} \mathrm{O}_{2}\right.$ production and lipid peroxidation (MDA)) and antioxidative enzyme (SOD, CAT, POD) activity were examined in both cultivars (Figure 6 and Figure S3). In Chardonnay, $\mathrm{H}_{2} \mathrm{O}_{2}$ production increased after $20 \mathrm{~d}$ of DS, while MDA content increased after $8 \mathrm{~d}$ of DS. These changes were followed by a decrease of SOD and increase of CAT and POD activities, mainly in response to moderate stress (Figure 6). Xynisteri subjected to DS had increased MDA and $\mathrm{H}_{2} \mathrm{O}_{2}$ production, accompanied by the increased SOD activity and decreased CAT and POD, in general, with more pronounced effects at $20 \mathrm{~d}$ of DS (Figure 6).

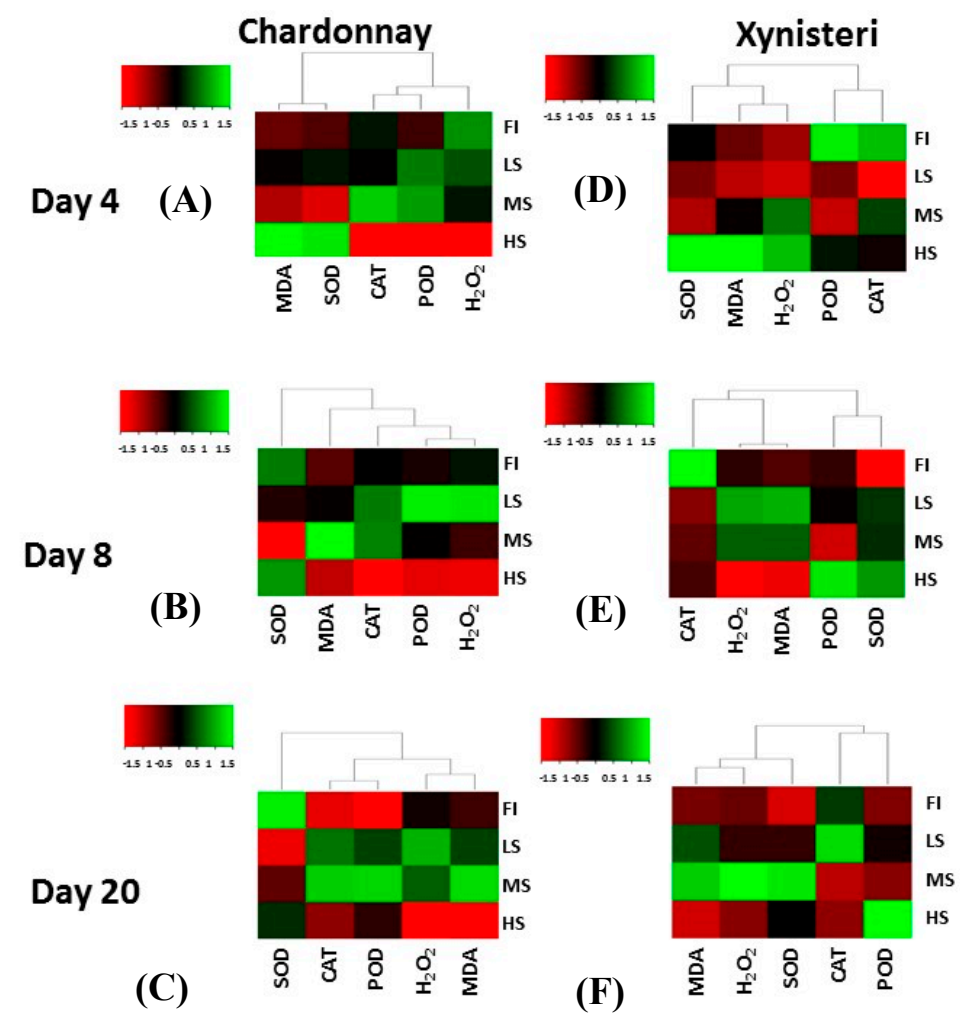

Figure 6. Relative changes in damage index (malondialdehyde (MDA), $\mathrm{H}_{2} \mathrm{O}_{2}$ ) and antioxidative enzymes (superoxide dismutase (SOD), catalase (CAT), peroxidase (POD)) after exposure of grapevine cultivars, Chardonnay (A-C) and Xynisteri (D-F), to water and heat stress. Heat map representing relative composition level of molecules traits after 4, 8 and $20 \mathrm{~d}$ of light water stress (LS) with $80 \%$ of the FI, moderate water stress (MS) with $50 \%$ of the FI, and heat stress (HS) as compared to control (full irrigation, FI) plants. Red shades indicate the lower level (less than -1.5 fold), deep red corresponds to -1 fold, black signifies that the level is not different from the control, deep green corresponds to 1 fold, clear green indicates that the level is more than 1.5-fold higher than the control. MDA and $\mathrm{H}_{2} \mathrm{O}_{2}$ are expressed in $\mu \mathrm{mol} / \mathrm{g}$; SOD, CAT and POD in units/mg protein.

Chardonnay plants subjected to HS showed a decrease of MDA and $\mathrm{H}_{2} \mathrm{O}_{2}$ production, associated to a decreased SOD and increased POD activity at $20 \mathrm{~d}$. Interestingly, SOD activity increased only at the early stage (i.e., $4 \mathrm{~d}$ ) of short-term HS, and decreased thereafter (Figure 6). In Xynisteri, MDA and $\mathrm{H}_{2} \mathrm{O}_{2}$ production increased only at the early stage (i.e., $4 \mathrm{~d}$ ) of short-term HS. An activation of SOD (at $>4 \mathrm{~d}$ ) and POD (at $>8 \mathrm{~d}$ ) activities was observed. Both MDA and $\mathrm{H}_{2} \mathrm{O}_{2}$ decreased following 8 and $20 \mathrm{~d}$ of HS.

\section{Discussion}

The results of the present study demonstrated that Xynisteri, a Cypriot indigenous cultivar, expressed and maintained some adaptive traits to environmental challenges of climate change 
compared to Chardonnay, an international cultivar. Indeed, both cultivars were affected more by the short-term drought stress than the heat stress conditions. Under stress conditions, plants develop adaptive mechanisms that reflect their sensitivity or tolerance to the challenged stress [42]. Therefore, leaf stomata closure decreased the photosynthesis and stomatal conductance as a result of drought stress [43]. Stomata closure to limit water loss by evapotranspiration during drought periods is an early physiological response that decreases the risk of hydraulic failure [44]. These adaptive processes are, in most cases, accompanied by hormonal changes including synthesis of abscisic acid in roots and its transport to the shoot and leaves. They act as a main signaling pathway in plants subjected to drought stress and control stomatal closure [44-46]. Recent studies indicated that stomatal conductance is controlled by hydraulic signals, abscisic acid and/or their interaction in response to drought stress [47]. Moreover, differences in leaf anatomical structure may affect the photosynthetic rates by changing the $\mathrm{CO}_{2}$ diffusion rate from ambient air to carboxylation sites in the chloroplast, as documented in apple leaves [11]. As such, leaf structure of the examined grapevine cultivars should be considered in future studies.

Chlorophyll is also sensitive to environmental challenges, thereby impacting photosynthetic performance and plant growth, as a positive correlation between chlorophyll content and photosynthetic rates has been reported [10]. Chlorophyll content is expected to be decreased in plants subjected to drought stress, through the suppression of key enzymes involved in its synthesis or the activation of its degradation $[11,48]$. Chlorophyll content was transiently increased at $8 \mathrm{~d}$ in Chardonnay, then decreased at $20 \mathrm{~d}$, while in Xynisteri chlorophyll content increased after $20 \mathrm{~d}$ of drought stress. This fluctuation of chlorophyll content might be related to the susceptibility to the short-term exposure to DS (i.e., 4 or $8 \mathrm{~d}$ ). A decrease of leaf chlorophyll content was also observed in another endemic red cultivar in Cyprus (namely Maratheftiko; Chrysargyris et al. [33]) or even in grapevines that were exposed to drought stress for a longer period of $45 \mathrm{~d}$ [49]. However, in mature grapevines that were 14 years old, chlorophyll content was unchanged in nonirrigated compared to irrigated plants [50], and this could be dependent on cultivar tolerance, plant age and the intensity of environmental stress. However, short-term exposure to HS did not affect chlorophyll content. This could be related to some thermotolerance capacity of grapevine cultivars.

Photosynthesis is one of the main processes affected by drought, and because of stomatal closure, both water loss and carbon flux to the carboxylation sites decrease [51]. Xynisteri is considered a drought-tolerant cultivar, while it responds impressively under a full irrigation regime by increasing the rates of photosynthesis and stomatal conductance. However, under DS conditions, photosynthesis and stomatal conductance decrease, slowing down the metabolic activity and adapting to the new DS conditions. This is consistent with other observations in a red cultivar resistant to DS as Xynisteri [33]. Such adaptation was not evidenced for the Chardonnay cultivar, as different cultivars exhibit different drought signaling mechanisms and abilities to withstand water stress [14]. Differences in stomatal response were also observed under DS among the examined cultivars, even when they were grown under the same environment and soil. Although additional proof is needed, this result could be attributed to changes in either hormonal status or accumulation of protective molecules (osmolytes, antioxidants), as suggested for other cultivars [20]. Short-term DS alters the grapevine metabolism and decreases leaf growth rate, in order to maintain an optimal leaf water state, by avoiding excessive water loss through transpiration [52]. Xynisteri also reacted to HS by lowering its metabolic activity through reduction of photosynthesis, stomatal conductance and internal $\mathrm{CO}_{2}$ concentration, mainly after $8 \mathrm{~d}$ of stress. In the case of Chardonnay, the leaf stomata were not closed in response to HS, but surprisingly, stomatal conductance was increased, with probably greater water losses from evapotranspiration and decreased photosynthetic rates.

Under drought stress, polyphenols, antioxidant activity (as assayed by FRAP) and flavonoid content were increased in Xynisteri but decreased in Chardonnay after $20 \mathrm{~d}$ of stress conditions. Similar results to Xynisteri were found in the Cypriot red indigenous cultivar Maratheftiko [33]. It has been shown that the increased flavonoid content is related to the decreased proline levels under stress 
conditions. This is consistent with the altered flux of nitrogen and carbon, which are used for flavonoids or proline synthesis [53,54]. Further proof is needed.

Stressed plants trigger enzymatic and nonenzymatic mechanisms of protection to scavenge and detoxify ROS $[34,55]$. The first target of ROS is to damage cell membranes. This increases lipid peroxidation and is highly correlated with the increase of MDA concentration. Beis and Patakas [14] reported that Mavrodafni grapevines had a higher MDA content compared to Sabatiano plants following DS. Here, we showed that the activity of antioxidative enzymes was significantly increased in water-stressed plants, following the increments of MDA and $\mathrm{H}_{2} \mathrm{O}_{2}$. These reactions were more pronounced in the Xynisteri cultivar than in Chardonnay. The enzyme activities were more precocious in Xynisteri in response to both DS and HD. The activation of antioxidative mechanisms is closely related to the genotypic ability to adapt to various environmental stresses including drought [56]. Initially, plants activate SOD to dismutate the superoxide ion and produce $\mathrm{H}_{2} \mathrm{O}_{2}$; thereafter, CAT, APX and POD are activated to detoxify the $\mathrm{H}_{2} \mathrm{O}_{2}$ into nontoxic components [33]. Nonetheless, the capacity of the plant to rapidly regulate the antioxidant system has been found to be closely associated with reduced oxidative damage and, therefore, drought tolerance in different species [14,57,58]. Nevertheless, activation of enzymes against ROS should not be generalized, as Doupis et al. [54] stated that the detoxification of ROS induced by drought, UV-B radiation and their combination was associated with the accumulation of proline in response to water deficit rather than the action of antioxidants.

It is not surprising that under semidry seasons and heat waves in Cyprus, Xynisteri is a well-adapted native cultivar. Drought-resistant cultivars can be cultivated without requiring irrigation, which is an important asset for sustainability, in a context where water resources become increasingly scarce [59]. Other strategies on water scarcity include the modification of training systems (e.g., goblet bush vines, or trellised vineyards at wider row spacing) or selecting soils with greater water holding capacity [59]. Noticeably, a substantial decrease in the water content in soil (Figure 1) under heat stress condition was observed despite the fact that the crop was fully irrigated. This could be the first response of HS with the reduction of soil water content, which causes light drought stress to the crop, and can be accumulated during plant growth period. Therefore, in cases of high temperatures that might cause HS, the current irrigation management practices (full irrigation for Chardonnay and dry-farmed Xynisteri) need to be reconsidered, as the effects of HS might cause water shortages to crops. Plantations of Xynisteri outside Cyprus would probably survive without irrigation in most regions, which is a big leap forward in terms of sustainability. Before doing so, the potential quality of Xynisteri outside Cyprus should, of course, also be taken into account. Normally, plants grown outdoors undergo more than one stress condition at the same time; thus, the combination of HS and DS could have adverse effects.

\section{Conclusions}

Drought and heat stress significantly affected physiological and biochemical parameters of the examined grapevine cultivars. Under drought and heat stress conditions, grapevines favored the increase in antioxidant enzyme activities to scavenge and detoxify ROS accumulation, with more pronounced effects in the indigenous cultivar, Xynisteri. Plant adaptation to DS included closure of stomata and the reduction of plant photosynthetic rates, and Xynisteri responded successfully to that. According to this study, we can conclude that the Chardonnay cultivar showed comparatively poorer physiological and biochemical properties than that of Xynisteri. The combined negative effects of environmental stresses need to be further explored, as it is a common issue facing climate change challenges in agriculture and crop production. Further studies on indigenous cultivars versus the international ones will add knowledge on the mechanisms adapted by grapevines through the decades to challenge climate change and specific edaphoclimatic conditions of an area. Moreover, exploitation of climate change effects on grapevines should take place at commercial vineyards, examining the impacts of climate change on grapevine productivity and/or quality of the grapes/juice. 
Supplementary Materials: The following are available online at http://www.mdpi.com/2073-4395/10/2/249/s1, Figure S1: Mean temperature and relative humidity for outdoors and indoors (greenhouse) during the drought and heat stress experiment; Figure S2: Impact of short-term drought and heat stress on the content of phenols, flavonoids and antioxidant activity in two grapevine cultivars, Chardonnay and Xynisteri; Figure S3: Impact of short-term drought and heat stress on $\mathrm{H}_{2} \mathrm{O}_{2}$ and malondialdehyde (MDA) contents, and activity of antioxidative enzymes in the leaves of two grapevine cultivars, Chardonnay and Xynisteri; Figure S4. Impact of short-term drought and heat stress on photosynthetic rate in two grapevine cultivars, Chardonnay and Xynisteri; Table S1: Soil physicochemical properties.

Author Contributions: Conceptualization, N.T. and A.A.; Data curation, N.T., A.C. and A.A.; Formal analysis, N.T. and A.C.; Funding acquisition, N.T.; Investigation, N.T. and A.C.; Methodology, N.T. and A.C.; Project administration, N.T. and A.A.; Resources, N.T.; Software, A.C.; Supervision, N.T.; Validation, N.T, A.C. and A.A.; Visualization, N.T.; Writing—original draft, N.T. and A.C.; Writing—review \& editing, N.T., A.C. and A.A. All authors have read and agreed to the published version of the manuscript.

Funding: This research received no external funding.

Acknowledgments: This research has been co-financed by the European Union (ERA-NET Cofound FACCE SURPLUS Call of Horizon 2020- FACCE JPI) and Cyprus Research Promotion Foundation, in the frame of the collaborative international consortium "Vitismart" project.

Conflicts of Interest: The authors declare no conflict of interest.

\section{References}

1. Estravis-Barcala, M.; Mattera, M.G.; Soliani, C.; Bellora, N. Molecular bases of responses to abiotic stress in trees. J. Exp. Bot. 2019, 1-15. [CrossRef] [PubMed]

2. Krasensky, J.; Jonak, C. Drought, salt, and temperature stress-induced metabolic rearrangements and regulatory networks. J. Exp. Bot. 2012, 63, 1593-1608. [CrossRef] [PubMed]

3. Munné-Bosch, S.; Queval, G.; Foyer, C.H. The impact of global change factors on redox signaling underpinning stress tolerance. Plant Physiol. 2013, 161, 5-19. [CrossRef] [PubMed]

4. Wang, W.; Vinocur, B.; Altman, A. Plant responses to drought, salinity and extreme temperatures: Towards genetic engineering for stress tolerance. Planta 2003, 218, 1-14. [CrossRef] [PubMed]

5. Chaves, M.M.; Maroco, J.P.; Pereira, J.S. Understanding plant responses to drought-From genes to the whole plant. Funct. Plant Biol. 2003, 30, 239-264. [CrossRef]

6. Pinheiro, C.; Chaves, M.M. Photosynthesis and drought: Can we make metabolic connections from available data? J. Exp. Bot. 2011, 62, 869-882. [CrossRef]

7. Kulkarni, M.; Tushar, B.; Sushama, C. Anatomical variability in grape (Vitis vinifera) genotypes in relation to water use efficiency (WUE). Am. J. Plant Physiol. 2007, 2, 36-43.

8. Patakas, A.; Noitsakis, B.; Chouzouri, A. Optimization of irrigation water use in grapevines using the relationship between transpiration and plant water status. Agric. Ecosyst. Environ. 2005, 106, $253-259$. [CrossRef]

9. Kofidis, G.; Bozabalidis, A.; Chartzoulakis, K. Leaf anatomical alterations induced by drought stress in two avocado cultivars. J. Biol. Res. 2004, 1, 115-120.

10. Vemmos, S.N.; Petri, E.; Stournaras, V. Seasonal changes in photosynthetic activity and carbohydrate content in leaves and fruit of three fig cultivars (Ficus carica L.). Sci. Hortic. 2013, 160, 198-207. [CrossRef]

11. Bhusal, N.; Bhusal, S.J.; Yoon, T.M. Comparisons of physiological and anatomical characteristics between two cultivars in bi-leader apple trees (Malus $\times$ domestica Borkh.). Sci. Hortic. 2018, 231, 73-81. [CrossRef]

12. Karam, G.N. Biomechanical model of the xylem vessels in vascular plants. Ann. Bot. 2005, 95, 1179-1186. [CrossRef] [PubMed]

13. Fraga, H.; García de Cortázar Atauri, I.; Malheiro, A.C.; Santos, J.A. Modelling climate change impacts on viticultural yield, phenology and stress conditions in Europe. Glob. Chang. Biol. 2016, 22, 3774-3788. [CrossRef] [PubMed]

14. Beis, A.; Patakas, A. Relative contribution of photoprotection and anti-oxidative mechanisms to differential drought adaptation ability in grapevines. Environ. Exp. Bot. 2012, 78, 173-183. [CrossRef]

15. Chaves, M.M.; Santos, T.P.; Souza, C.R.; Ortuño, M.F.; Rodrigues, M.L.; Lopes, C.M.; Maroco, J.P.; Pereira, J.S. Deficit irrigation in grapevine improves water-use efficiency while controlling vigour and production quality. Ann. Appl. Biol. 2007, 150, 237-252. [CrossRef] 
16. Williams, L.E.; Baeza, P. Relationships among ambient temperature and vapor pressure deficit and leaf and stem water potentials of fully irrigated, field-grown grapevines. Am. J. Enol. Vitic. 2007, 58, 173-181.

17. Chaves, M.M.; Flexas, J.; Pinheiro, C. Photosynthesis under drought and salt stress: Regulation mechanisms from whole plant to cell. Ann. Bot. 2009, 103, 551-560. [CrossRef]

18. Hall, A.; Jones, G.V. Effect of potential atmospheric warming on temperature-based indices describing australian winegrape growing conditions. Aust. J. Grape Wine Res. 2009, 15, 97-119. [CrossRef]

19. Stock, M.; Gerstengarbe, F.W.; Kartschall, T.; Werner, P.C. Reliability of climate change impact assessments for viticulture. Acta Hortic. 2005, 689, 29-39. [CrossRef]

20. Beis, A.; Patakas, A. Differential physiological and biochemical responses to drought in grapevines subjected to partial root drying and deficit irrigation. Eur. J. Agron. 2015, 62, 90-97. [CrossRef]

21. Dagianta, E.; Goumas, D.; Manios, T.; Tzortzakis, N. The use of treated wastewater and fertigation in greenhouse pepper crop as affecting growth and fruit quality. J. Water Reuse Desalin. 2014, 4, 92-99. [CrossRef]

22. Duchene, E.; Schneider, C. Grapevine and climatic changes: A glance at the situation in Alsace. Agron. Sustain. Dev. 2005, 25, 93-99. [CrossRef]

23. Mullins, M.G.; Bouquet, A.; Williams, L.E. Biology of the Grapevine; Cambridge University Press: Cambridge, UK; New York, NY, USA, 1992; ISBN 0521305071.

24. De Orduña, R.M. Climate change associated effects on grape and wine quality and production. Food Res. Int. 2010, 43, 1844-1855. [CrossRef]

25. Van Leeuwen, C.; Destrac-Irvine, A. Modified grape composition under climate change conditions requires adaptations in the vineyard. Oeno One 2017, 51, 147-154. [CrossRef]

26. Hawker, J.S. Effect of temperature on lipid, starch and enzymes of starch metabolism in grape, tomato and broad bean leaves. Phytochemistry 1982, 21, 33-36. [CrossRef]

27. Hale, C.R.; Buttrose, M.S. Effect of temperature on ontogeny of berries of Vitis vinifera L. cv. Cabernet Sauvignon. J. Am. Soc. Hortic. Sci. 1974, 99, 390-394.

28. Coombe, B.G. Influence of temperature on composition and quality of grapes. Acta Hortic. 1987, 23-36. [CrossRef]

29. Teixeira, A.; Eiras-Dias, J.; Castellarin, S.D.; Gerós, H. Berry phenolics of grapevine under challenging environments. Int. J. Mol. Sci. 2013, 14, 18711-18739. [CrossRef]

30. Duchêne, É. How can grapevine genetics contribute to the adaptation to climate change? Oeno One 2016, 50, 113-124. [CrossRef]

31. Pons, A.; Allamy, L.; Schüttler, A.; Rauhut, D.; Thibon, C.; Darriet, P. What is the expected impact of climate change on wine aroma compounds and their precursors in grape? Oeno One 2017, 51, 141-146. [CrossRef]

32. Selote, D.S.; Bharti, S.; Khanna-Chopra, R. Drought acclimation reduces O2-. accumulation and lipid peroxidation in wheat seedlings. Biochem. Biophys. Res. Commun. 2004, 314, 724-729. [CrossRef]

33. Chrysargyris, A.; Xylia, P.; Antoniou, O.; Tzortzakis, N. Climate change due to heat and drought stress can alter the physiology of Maratheftiko local cyprian grapevine variety. J. Water Clim. Chang. 2018, 9, 1-13. [CrossRef]

34. Chrysargyris, A.; Papakyriakou, E.; Petropoulos, S.A.; Tzortzakis, N. The combined and single effect of salinity and copper stress on growth and quality of Mentha spicata plants. J. Hazard. Mater. 2019, 368, 584-593. [CrossRef] [PubMed]

35. Türkan, I.; Demiral, T. Recent developments in understanding salinity tolerance. Environ. Exp. Bot. 2009, 67, 2-9. [CrossRef]

36. Hatmi, S.; Gruau, C.; Trotel-Aziz, P.; Villaume, S.; Rabenoelina, F.; Baillieul, F.; Eullaffroy, P.; Clément, C.; Ferchichi, A.; Aziz, A. Drought stress tolerance in grapevine involves activation of polyamine oxidation contributing to improved immune response and low susceptibility to Botrytis cinerea. J. Exp. Bot. 2015, 66, 775-787. [CrossRef]

37. Chrysargyris, A.; Laoutari, S.; Litskas, V.D.; Stavrinides, M.C.; Tzortzakis, N. Effects of water stress on lavender and sage biomass production, essential oil composition and biocidal properties against Tetranychus urticae (Koch). Sci. Hortic. 2016, 213, 96-103. [CrossRef] 
38. Chondraki, S.; Tzerakis, C.; Tzortzakis, N. Influence of sodium chloride and calcium foliar spray on hydroponically grown parsley in Nutrient Film Technique system. J. Plant Nutr. 2012, 35, 1457-1467. [CrossRef]

39. Chrysargyris, A.; Drouza, C.; Tzortzakis, N. Optimization of potassium fertilization/nutrition for growth, physiological development, essential oil composition and antioxidant activity of Lavandula angustifolia Mill. J. Soil Sci. Plant Nutr. 2017, 17, 291-306. [CrossRef]

40. Xylia, P.; Chrysargyris, A.; Botsaris, G.; Tzortzakis, N. Potential application of spearmint and lavender essential oils for assuring endive quality and safety. Crop Prot. 2017, 102, 94-103. [CrossRef]

41. Xylia, P.; Clark, A.; Chrysargyris, A.; Romanazzi, G.; Tzortzakis, N. Quality and safety attributes on shredded carrots by using Origanum majorana and ascorbic acid. Postharvest Biol. Technol. 2019, 155, 120-129. [CrossRef]

42. Tardieu, F.; Simonneau, T.; Muller, B. The physiological basis of drought tolerance in crop plants: A scenario-dependent probabilistic approach. Annu. Rev. Plant Biol. 2018, 69, 733-759. [CrossRef] [PubMed]

43. Bhusal, N.; Han, S.G.; Yoon, T.M. Impact of drought stress on photosynthetic response, leaf water potential, and stem sap flow in two cultivars of bi-leader apple trees (Malus $\times$ domestica Borkh.). Sci. Hortic. 2019, 246, 535-543. [CrossRef]

44. Tombesi, S.; Nardini, A.; Frioni, T.; Soccolini, M.; Zadra, C.; Farinelli, D.; Poni, S.; Palliotti, A. Stomatal closure is induced by hydraulic signals and maintained by ABA in drought-stressed grapevine. Sci. Rep. 2015, 5, 1-12. [CrossRef] [PubMed]

45. Schachtman, D.P.; Goodger, J.Q.D. Chemical root to shoot signaling under drought. Trends Plant Sci. 2008, 13, 281-287. [CrossRef] [PubMed]

46. Davies, W.J.; Kudoyarova, G.; Hartung, W. Long-distance ABA signaling and its relation to other signaling pathways in the detection of soil drying and the mediation of the plant's response to drought. J. Plant Growth Regul. 2005, 24, 285-295. [CrossRef]

47. McAdam, S.A.M.; Brodribb, T.J. Hormonal dynamics contributes to divergence in seasonal stomatal behaviour in a monsoonal plant community. Plant Cell Environ. 2015, 38, 423-432. [CrossRef]

48. Haider, M.S.; Zhang, C.; Kurjogi, M.M.; Pervaiz, T.; Zheng, T.; Zhang, C.; Lide, C.; Shangguan, L.; Fang, J. Insights into grapevine defense response against drought as revealed by biochemical, physiological and RNA-Seq analysis. Sci. Rep. 2017, 7, 1-15. [CrossRef]

49. Maroco, J.P.; Rodrigues, M.L.; Lopes, C.; Chaves, M.M. Limitations to leaf photosynthesis in field-grown grapevine under drought - Metabolic and modelling approaches. Funct. Plant Biol. 2002, 29, 451-459. [CrossRef]

50. Chaumont, M.; Osorio, M.L.; Chaves, M.M.; Vanacker, H.; Morot-Gaudry, J.F.; Foyer, C.H. The absence of photoinhibition during the mid-morning depression of photosynthesis in Vitis vinifera grown in semi-arid and temperate climates. J. Plant Physiol. 1997, 150, 743-751. [CrossRef]

51. Escalona, J.; Flexas, J.; Medrano, H. Drought effects on water flow, photosynthesis and growth of potted grapevines. Vitis 2002, 41, 57-62.

52. Tardieu, F.; Granier, C.; Muller, B. Modelling leaf expansion in a fluctuating environment: Are changes in specific leaf area a consequence of changes in expansion rate? New Phytol. 1999, 143, 33-43. [CrossRef]

53. Hofmann, R.W.; Campbell, B.D.; Bloor, S.J.; Swinny, E.E.; Markham, K.R.; Ryan, K.G.; Fountain, D.W. Responses to UV-B radiation in Trifolium repens L. - Physiological links to plant productivity and water availability. Plant Cell Environ. 2003, 26, 603-612. [CrossRef]

54. Doupis, G.; Chartzoulakis, K.; Beis, A.; Patakas, A. Allometric and biochemical responses of grapevines subjected to drought and enhanced ultraviolet-B radiation. Aust. J. Grape Wine Res. 2011, 17, 36-42. [CrossRef]

55. Apel, K.; Hirt, H. Reactive oxygen species: Metabolism, oxidative stress, and signal transduction. Annu. Rev. Plant Biol. 2004, 55, 373-399. [CrossRef] [PubMed]

56. Ramachandra, R.A.; Chaitanya, K.V.; Jutur, P.P.; Sumithra, K. Differential antioxidative responses to water stress among five mulberry (Morus alba L.) cultivars. Environ. Exp. Bot. 2004, 52, 33-42. [CrossRef]

57. Sofo, A.; Dichio, B.; Xiloyannis, C.; Masia, A. Antioxidant defences in olive trees during drought stress: Changes in activity of some antioxidant enzymes. Funct. Plant Biol. 2005, 32, 45-53. [CrossRef] 
58. Wang, W.-B.; Kim, Y.-H.; Lee, H.-S.; Kim, K.-Y.; Deng, X.-P.; Kwak, S.-S. Analysis of antioxidant enzyme activity during germination of alfalfa under salt and drought stresses. Plant Physiol. Biochem. PРB 2009, 47, 570-577. [CrossRef]

59. Van Leeuwen, C.; Destrac-Irvine, A.; Dubernet, M.; Duchêne, E.; Gowdy, M.; Marguerit, E.; Pieri, P.; Parker, A.; De Rességuier, L.; Ollat, N. An update on the impact of climate change in viticulture and potential adaptations. Agronomy 2019, 9, 514. [CrossRef]

(c) (1) (C) 2020 by the authors. Licensee MDPI, Basel, Switzerland. This article is an open access article distributed under the terms and conditions of the Creative Commons Attribution (CC BY) license (http://creativecommons.org/licenses/by/4.0/). 